\title{
Multi-technique investigations of storm-time ionospheric irregularities over the São Luís equatorial station in Brazil
}

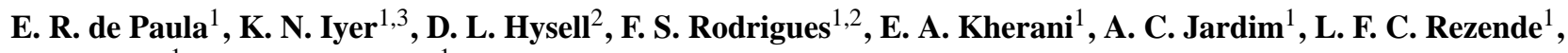 \\ S. G. Dutra ${ }^{1}$, and N. B. Trivedi ${ }^{1}$ \\ ${ }^{1}$ National Institute for Space Research (INPE), C.P. 515, 12.245-970, São José dos Campos, SP, Brazil \\ ${ }^{2}$ Cornell University, 2108 Snee Hall, Ithaca, NY, 14853, USA \\ ${ }^{3}$ Department of Physics, Saurashtra University, Rajkot, 360 005, India
}

Received: 7 January 2004 - Revised: 1 July 2004 - Accepted: 20 July 2004 - Published: 3 November 2004

\begin{abstract}
On 11 April 2001, a large magnetic storm occurred with SSC at 13:43 UT, and $D_{s t}$ reached below $-200 \mathrm{nT}$ after two southward $B_{z}$ excursions. The $K_{p}$ index during this storm reached 8 and remained high $(>4)$ for about $21 \mathrm{~h}$, and the São Luís magnetometer H component presented simultaneous oscillations and decreased substantially relative to the previous magnetically quiet days. This storm triggered strong ionospheric irregularities, as observed by a recently installed $30 \mathrm{MHz}$ coherent scatter radar, a digisonde, and a GPS scintillation receiver, all operating at the São Luís equatorial station $\left(2.33^{\circ} \mathrm{S}, 44^{\circ} \mathrm{W}\right.$, dip latitude $\left.1.3^{\circ} \mathrm{S}\right)$. The ionospheric conditions and the characteristics of the ionospheric irregularities observed by these instruments are presented and discussed. The VHF radar RTI (Range Time Intensity) echoes and their power spectra and spectral width for the storm night 11-12 April 2001, were used to analyse the nature and dynamics of the plasma irregularities and revealed the coexistence of many structures in the altitudinal range of $400-1200 \mathrm{~km}$, some locally generated and others that drifted from other longitudinal sectors. The radar data also revealed that the plumes had periodic eastward and westward zonal velocities after 22:20 UT, when well-developed quiet-time plumes typically drift eastward. Another interesting new observation is that the F-layer remained anomalously high throughout the 11-12 April 2001 storm night (21:00 UT to 09:00 UT next day) (the LT at São Luís is UT -3 h), as indicated by the digisonde parameters $h m \mathrm{~F} 2$ and $\mathrm{h}^{\prime} \mathrm{F}$, which is a condition favourable for spread $F$ generation and maintenance. The AE auroral index showed enhancements (followed by decreases) that are indicative of magnetospheric convection enhancements at about 15:00 UT, 20:00 UT and 22:00 UT on 11 April 2001 and at 00:20 UT (small amplitude) on 12 April 2001, associated with many $B_{z}$ fluctuations, including clear two southward incursions that gave rise to large and long lasting $K_{p}$ values and large negative $D_{s t}$
\end{abstract}

Correspondence to: E. R. de Paula

(eurico@dae.inpe.br) values. This intense auroral activity generated disturbance dynamo and prompt penetration electric fields that were responsible for the maintenance of the F-layer at a high altitude along the night of 11-12 April 2001. The short-lived F-region height rise seen between 16:00 to 18:00 UT on 11 April 2001 is probably due to the prompt penetration eastward electric fields of magnetospheric origin during the first IMF $B_{z}$ turning to south around 15:00 UT.

Key words. Ionosphere (ionospheric irregularities)

\section{Introduction}

Equatorial F-region ionospheric irregularities have been extensively studied from theoretical and experimental points of view (e.g. Woodman and La Hoz, 1976; Ossakow, 1981; Abdu et al., 1985, 2002; Kelley et al., 1996; Weber et al., 1996; Fejer, 1997b; Hysell and Woodman, 1997; Musman et al, 1997; Kil and Heelis, 1998; Beach and Kintner, 1999; Fejer et al., 1999; Basu et al., 2001). Long-term climatological and persistence studies of the irregularities have been recently performed with the JULIA radar at Jicamarca (Hysell and Burcham, 1998, 2002). Similar studies are being undertaken in the Brazilian equatorial zone using the São Luís radar (de Paula and Hysell, 2004).

The above studies showed that the Equatorial Spread F (ESF) has very large day-to-day variability during quiet and disturbed times, which is due to the various factors affecting the generation and growth of plasma interchange instabilities, and is still an enigmatic problem (Abdu, 2001). The most well recognized influences on irregularity growth are the height and vertical drift of the F-layer driven by the eastward electric field.

The study of ESF characteristics during geomagnetic storms gives important insight into the role of electric fields of magnetospheric origin in the irregularity process, is of interest in the broader context of magnetospheric-ionospheric 


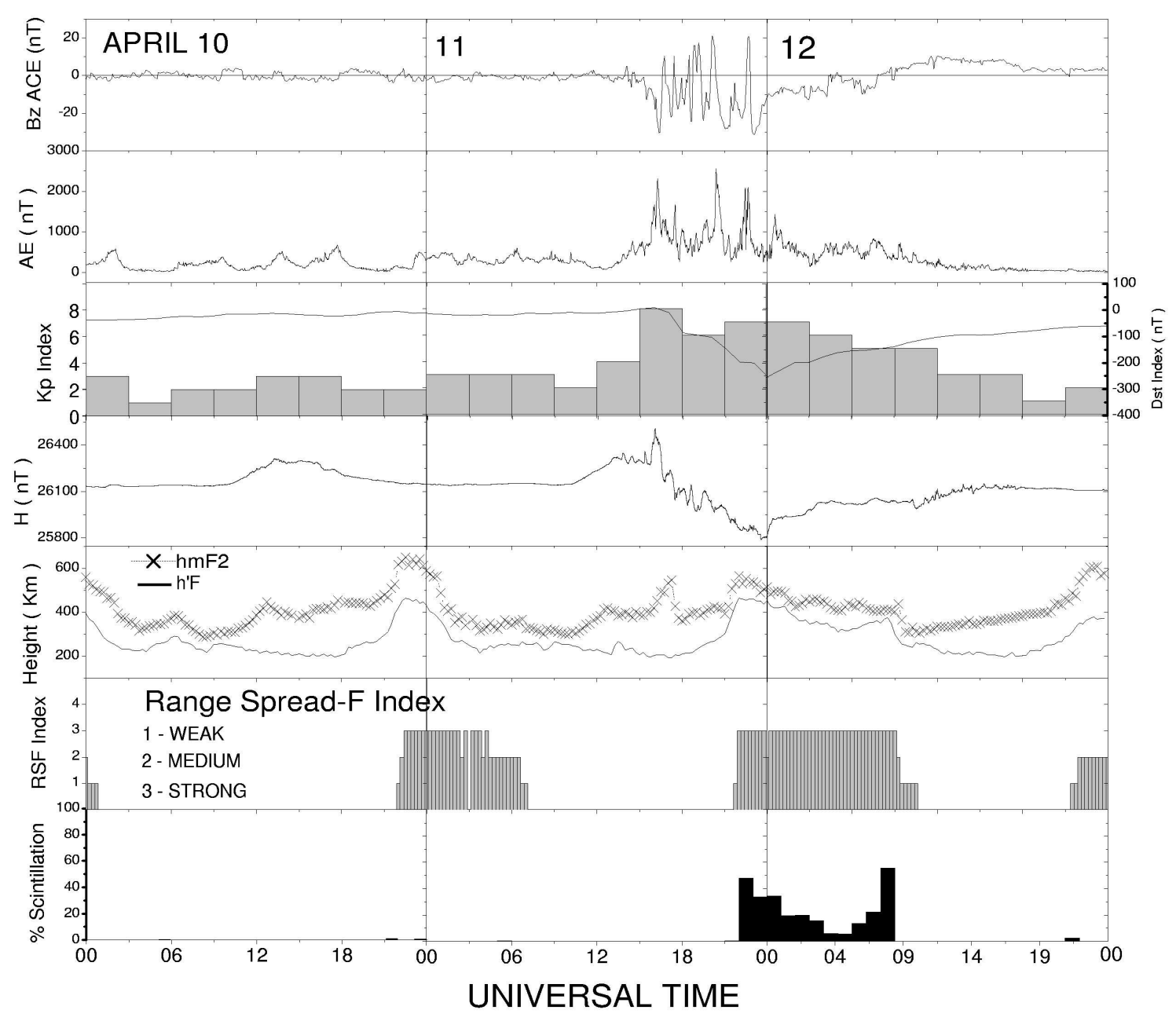

Fig. 1. IMF $B_{z}$ component in GSM coordinates provided by the ACE spacecraft (corrected to the propagation time up to the magnetopause boundary), AE auroral index, $K_{p}$ and $D_{s t}$ magnetic indices, São Luís magnetometer $\mathrm{H}$ component, São Luís digisonde parameters $h m \mathrm{~F} 2$ and $h^{\prime} \mathrm{F}$, and Range Spread F (RSF) index and Percentage of Occurrence of GPS amplitude scintillations with scintillation index $\mathrm{S}_{4}>0.1$, from 10 to 12 April 2001.

coupling (Reddy and Nishida, 1992) and in the impact on global VHF/UHF communications systems (Basu et al., 2001).

The magnetospheric electric field can, under favourable conditions, penetrate directly to low latitudes almost instantaneously (prompt penetration) and with a delay of 9 to $30 \mathrm{~h}$ through the disturbance dynamo mechanism (e.g. Kikuchi and Araki, 1979; Blanc and Richmond, 1980; Fejer, 1986; Fejer et al., 1990; Fejer and Scherliess, 1995; Scherliess and Fejer, 1997; Spiro et al., 1988). The disturbance dynamo electric field reduces the plasma ascent rate at equatorial latitudes during daylight but also reduces the descent rate at night, decreasing the threshold for inversion. Direct penetration can be eastward, lifting the equatorial plasma, or westward, lowering the plasma. At night, eastward direct electric field penetration could trigger ionospheric irregularities at any time of year since it lifts the plasma and creates favourable conditions for irregularities to grow. This effect can be intensified if the eastward direct penetration occurs in conjunction with the regular post-sunset pre-reversal enhancement driven by F-region dynamo action (Batista et al., 1991) or with disturbance dynamo action at night. Previous studies of this effect have mainly relied exclusively on either ionosonde data (Somayajulu et al., 1987; Reddy and Nishida, 1992; Abdu et al., 1995), incoherent scatter radar data (Fejer, 1997a), or VHF ionospheric scintillations (Aarons, 1991), which alone cannot give a complete perspective of the processes involved.

In this paper, a strong spread $F$ event observed at the São Luís equatorial station during the magnetic storm of 11-12 April 2001 is studied using a variety of instruments, including a VHF coherent scatter radar, a GPS receiver, a digisonde, and a magnetometer, which allowed us to detect irregularities with different scale sizes. In addition to these data sources, supporting geomagnetic data and indices from auroral latitudes are also used to establish the magnetospheric-ionospheric electrodynamic link. 


\section{Brief description of the systems}

The São Luís VHF radar (de Paula and Hysell, 2004) is a pulsed Doppler radar with interferometric capability that records raw data to tape while processing it in real time and displaying the results, in the form of spectrograms, on a Worldwide Web server (http://200.241.80.42). During data post processing, the scattered signal-to-noise ratios, Doppler velocities, and zonal irregularity drift velocities are typically computed for display in range-time image format. The autocovariance method (Woodman, 1985) is applied to time series data to calculate the signal-to-noise ratio, Doppler velocity and spectral width. The spectra are also calculated from the time series data by the Fast Fourier Transform method. The radar observation was performed with a vertically pointed beam having an east-west beamwidth of $10^{\circ}$ and a $10 \mathrm{~ms}$ IPP (Inter-Pulse-Period). The maximum unbiased vertical velocity is $\pm 250 \mathrm{~m} / \mathrm{s}$ and the range resolution is $2.5 \mathrm{~km}$. The GPS L1 band receiver, specially prepared to detect amplitude scintillation due to ionospheric irregularities, is a modified Gec-Plessey card installed in one microcomputer that collects data at a high rate (50 samples/s). A complete description of the GPS receiver can be found in Beach and Kintner (2001). The digisonde is a Lowell University 256 model (Reinisch et al., 1989) that sounds the ionosphere nominally every $15 \mathrm{~min}$ with a sweep frequency range from 2 to $20 \mathrm{MHz}$. The magnetometer is a 3-axis Fluxgate type with digital data recording capability. The GPS scintillation technique, in the present case, is sensitive to $400 \mathrm{~m}$ (Fresnel size) irregularities, the digisonde to kilometric irregularities, and the $30 \mathrm{MHz}$ coherent scatter radar to $5 \mathrm{~m}$ irregularities, so the spatial spectral evolution of the irregularities with different scale sizes can be studied at São Luís.

\section{São Luís multi-instrument data / results}

Figure 1 presents the IMF $B_{z}$ component in GSM coordinates provided by the ACE spacecraft (corrected to the propagation time up to the magnetopause boundary), the AE auroral index, the $K_{p}$ and $D_{s t}$ magnetic indices, the São Luís magnetometer H component, the São Luís digisonde parameters $h m \mathrm{~F} 2, \mathrm{~h}^{\prime} \mathrm{F}$, and Range Spread F (RFS) index and the percentage of occurrence of GPS amplitude scintillations with scintillation index $S_{4}>0.1$, from 10 to 12 April 2001. On 11 April 2001 the IMF $B_{z}$ component turned south at about 15:00 UT up to 18:00 UT and after some north-south fluctuations it turned again to south up to about 06:00 UT on 12 April 2001. The AE auroral index showed enhancements (followed by decreases) at about 15:00 UT, 20:00 UT and 22:00 UT on 11 April 2001 and at 00:20 UT (small amplitude) on 12 April 2001. The $D_{s t}$ index reached below $-200 \mathrm{nT}$ around 24:00 UT on the night of 11-12 April 2001 and the $K_{p}$ index reached 8 and remained high (>5) for many hours after the SSC. The São Luís magnetogram $\mathrm{H}$ component shows that the strong storm began at $\sim 13: 00$ UT (10:00 LT at São Luís) on 11 April 2001, extending up to

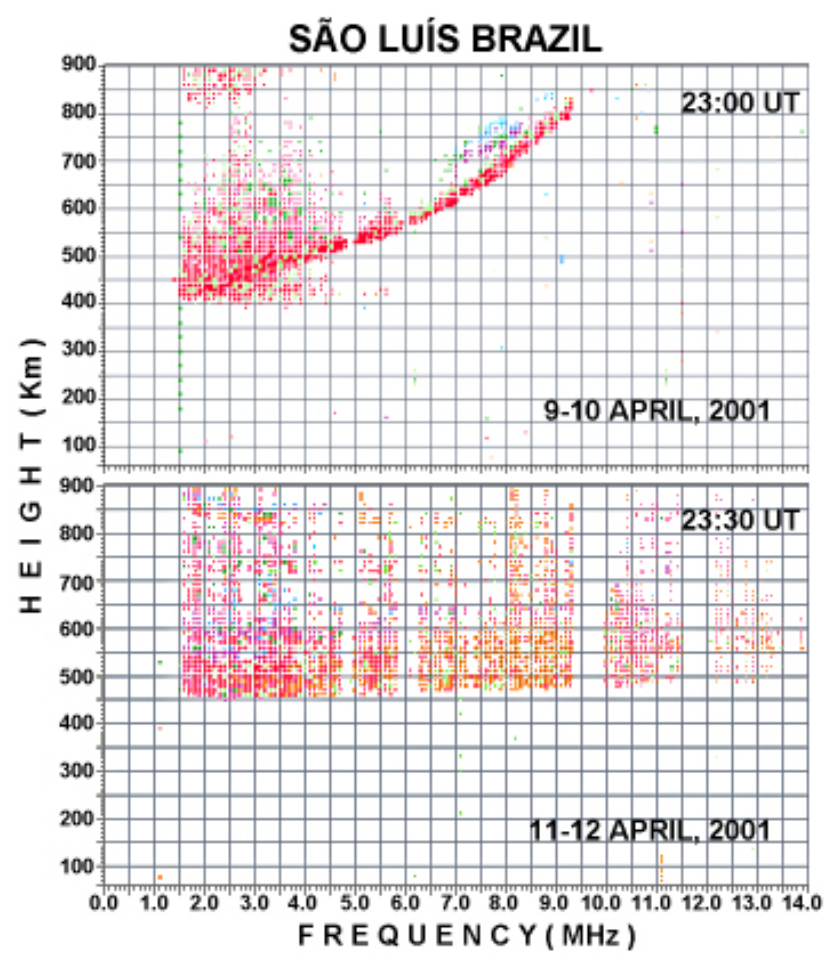

Fig. 2. An ionogram from 23:00 UT (20:00 LT) during a quiet control night (9-10 April 2001) (upper panel) and an ionogram for the storm night (11-12 April 2001) at 23:30 UT.

the morning of 12 April 2001 and revealed many oscillations during the storm period and decreased substantially relative to the previous quiet day.

The digisonde range spread $F$ was present (being in the end of spread $F$ season over Brazilian longitudes) on all nights of this period (10-12 April 2001) but with a longer duration and more intensity during the night of 11 12 April 2001, compared to the other nights of the period. Quiet-time spread $F$ is normally confined to the post sunsetmidnight time interval. On 11-12 April 2001, the $h m \mathrm{~F} 2$ and $\mathrm{h}^{\prime} \mathrm{F}$ parameters, and consequently the $\mathrm{F}$-layer, remained anomalously high all through the night with a very slow decay. Though $h m \mathrm{~F} 2$ could not be scaled precisely during strong spread $\mathrm{F}$, the evaluation of $\mathrm{h}^{\prime} \mathrm{F}$, even during strong spread $F$, is always expected to be a reliable parameter to infer the vertical movement of the bottomside F-layer. On 11 April 2001, the digisonde parameter $h m \mathrm{~F} 2$, that is the true height of the F2-layer density peak, was anomalously elevated (rather slowly) to higher altitudes from 16:00 to 18:00 UT and a simultaneous increase in the $\mathrm{H}$ component of the São Luís magnetogram was observed at this time interval, which indicates storm electric field penetration to low latitudes. But surprisingly, $\mathrm{h}^{\prime} \mathrm{F}$, the virtual height of the base of F-layer, does not show any corresponding rise. This may be because, from 16:00 to 18:00 UT, $h^{\prime} F$ is around $200 \mathrm{~km}$ and is controlled more by the recombination process than by the electric field. 


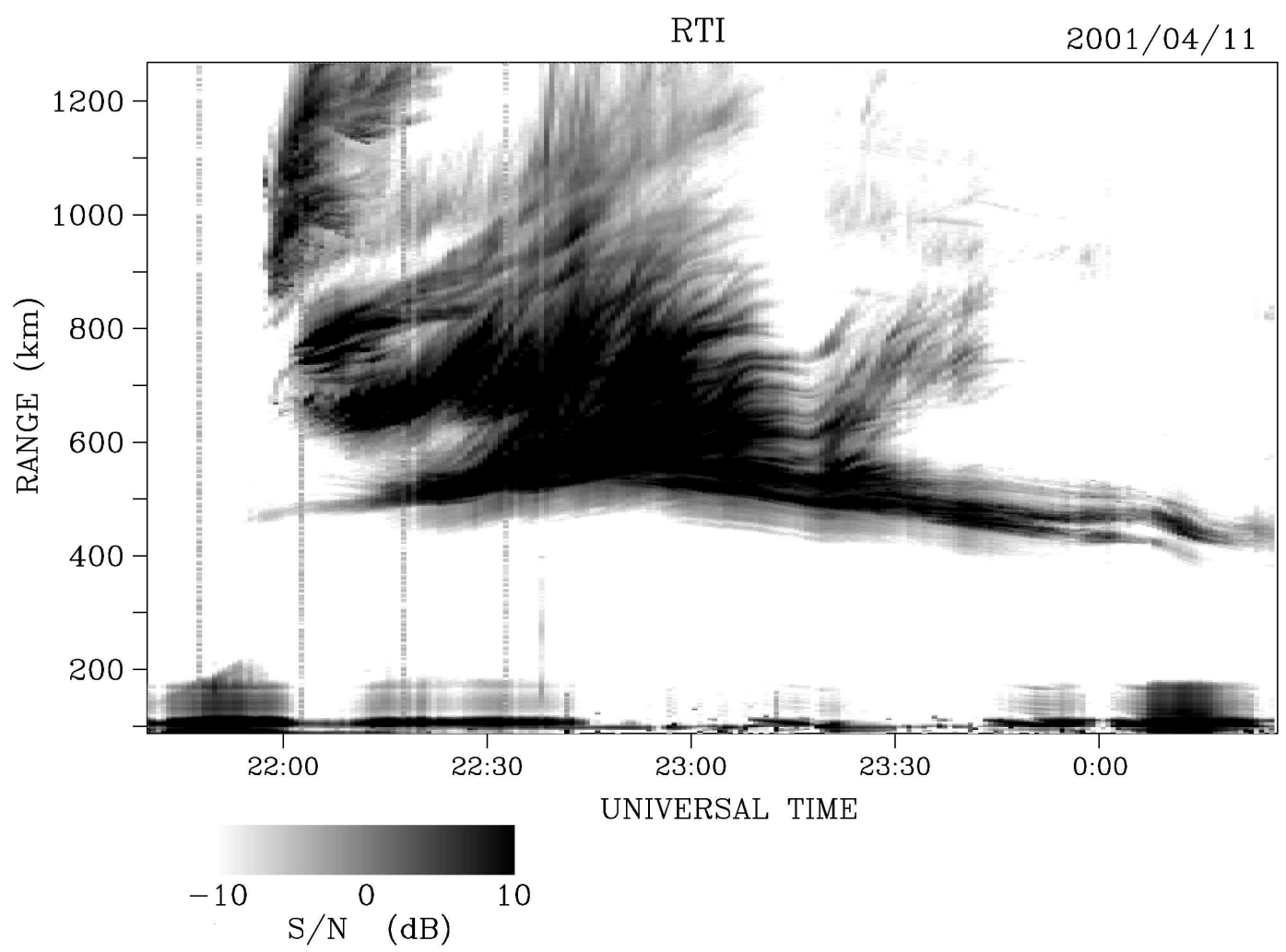

Fig. 3a. VHF radar RTI (Range-Time-Intensity) plot of the echoes from the ionospheric irregularities for the storm night of 11-12 April 2001.

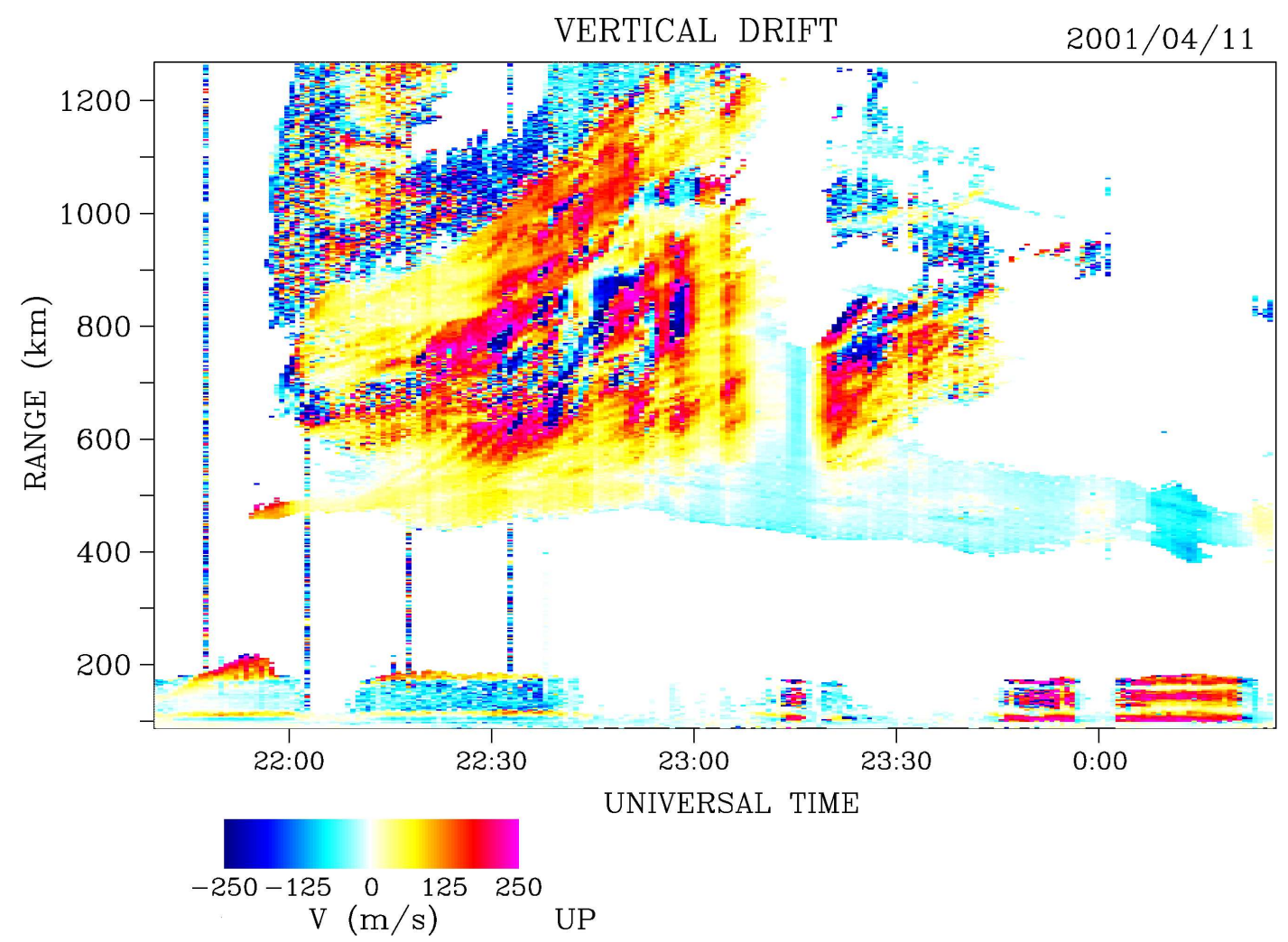

Fig. 3b. VHF radar vertical velocity plot of the echoes from the ionospheric irregularities for the storm night of 11-12 April 2001. 


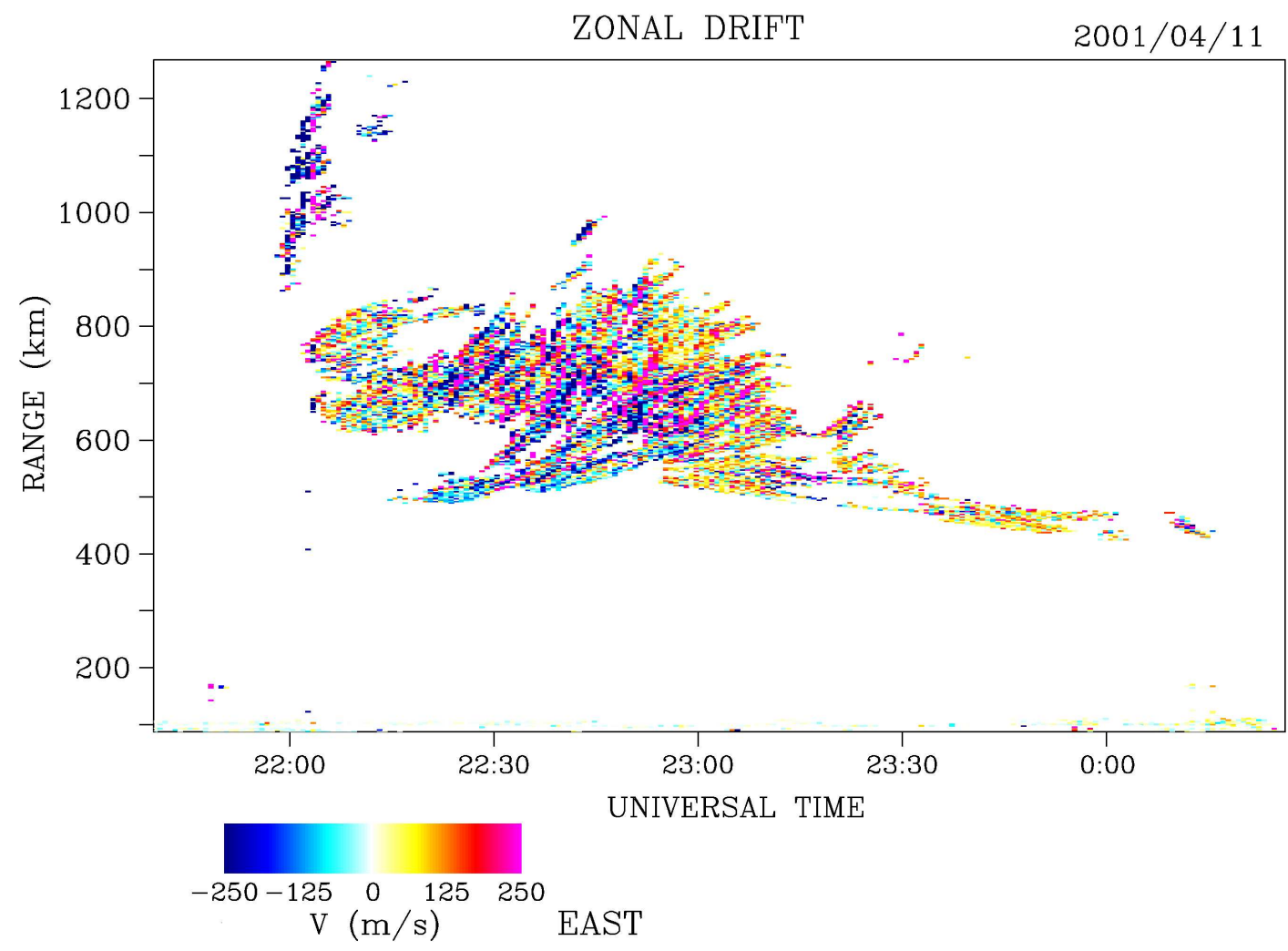

Fig. 3c. VHF radar zonal velocity plot of the echoes from the ionospheric irregularities for the storm night of 11-12 April 2001.

Two ionograms, one from 23:00 UT (20:00 LT) during a quiet control night (9-10 April 2001) (upper panel) and another in the storm night (11-12 April 2001) (lower panel) at 23:30 UT are shown in Fig. 2. We can observe that on the storm night, the F-layer had a small bottomside electron density gradient scale length $\mathrm{L}_{N}$, where $(1 / \mathrm{N})(\mathrm{dN} / \mathrm{dh})=\mathrm{L}_{N}^{-1}$, compared to the quiet night. Also, as the layer during the storm night remained at a high altitude, the ion-neutral collision frequency $v_{i n}$ was small which, conjugated with a small $\mathrm{L}_{N}$, are favourable conditions that contributed to a large instability growth rate whose simplest equation will be given in the next section.

During the night of 11-12 April 2001 (Fig. 1), the digisonde recorded range spread $F$, with a peak index of $3(P>200 \mathrm{~km}$ in range), and GPS L1 band scintillation $\left(\mathrm{S}_{4}>0.1\right)$, showed one large peak percentage of occurrence reaching 30-50\% from 22:00 to 01:00 UT and another peak of 55\% around 08:00 UT on 12 April 2001. On all other quiet nights 10-11 and 12-13 April, including the nights of 9-10 and 13-14 April (not shown here), the GPS scintillation occurrence remained below $5 \%$.

The São Luís VHF coherent backscatter radar also detected a strong ionospheric irregularity occurrence during the storm night of 11-12 April 2001. There are no radar data in the days close to the storm night. Figure 3 a shows the radar RTI (Range-Time-Intensity) plot of the echoes from the 5-m ionospheric irregularities along with their vertical (Fig. 3b) and zonal (Fig. 3c) velocities. Usually the Doppler velocity should be consistent with the ranging rate of the correspond- ing irregular structure. In the case where they are not consistent, this implies that the vertical velocities are aliased. The rough estimate of the unaliased velocities can be obtained by adding $500 \mathrm{~m} / \mathrm{s}$ to the aliased velocity. For example, the structure observed at 900 to $1200 \mathrm{~km}$ height during 21:50 to 22:20 UT in Fig. 3a has a large ascending rate but shows predominantly downward Doppler velocities, as is clear in Fig. 3b. These are certainly aliased velocities and need to be corrected by adding $500 \mathrm{~m} / \mathrm{s}$. Thus, the real velocity of this structure is upward, not downward. Vertical traces in Figs. $3 \mathrm{a}$ and $\mathrm{b}$, at 15-min intervals, are due to digisonde interference. Figure 3a (RTI) shows large topside layers (plumes) from 21:50 to 23:40 UT, reaching more than $1200 \mathrm{~km}$ in altitude. The typical quiet time bottom-type precursor layer, a thin layer with a small vertical velocity normally preceding the plumes, appears at about $500 \mathrm{~km}$ and is connected just with the lower structure that grew up around 22:35 UT. The two others structures that appeared in the altitude range of 600 to $800 \mathrm{~km}$ at 22:00 UT, evolved to very high altitudes, and were moving to the east (Fig. 3c), but did not show the bottom-type precursor layer and could be not locally generated. One short-lived plume patch, located above $900 \mathrm{~km}$ in altitude and drifting upward with a large velocity (Fig. 3b) and predominantly westward (Fig. 3c), was observed from 21:50 to 22:20 UT. Such high altitude and westward moving irregular structure, in agreement with the observations reported earlier by Basu et al. (1996) during disturbed periods, was attributed to the effect of the disturbance dynamo. 


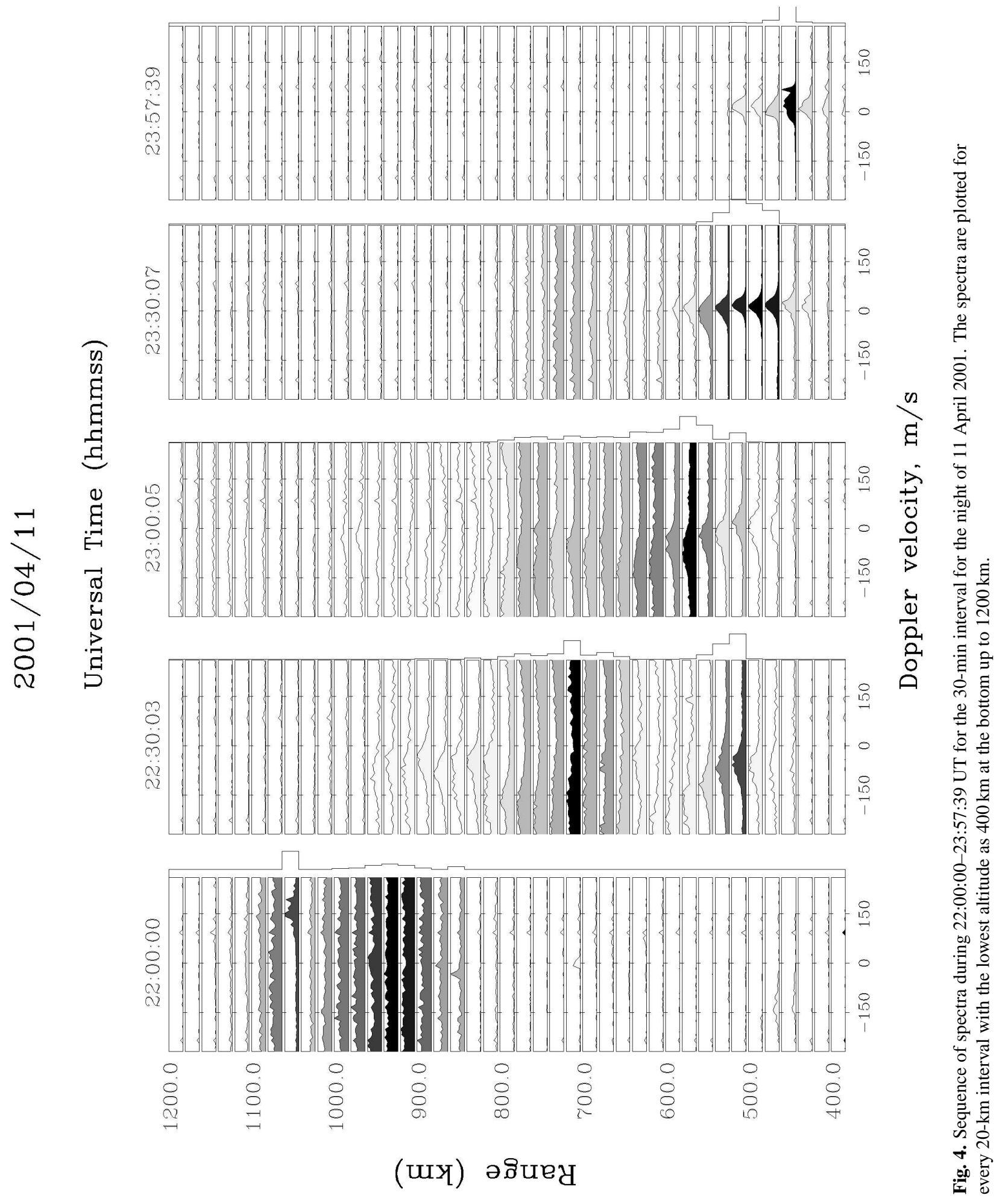


In the last paragraph of this section a discussion based on the spectra for this night gives support to the above observations.

Normally, the irregularities are triggered after an upward layer drift driven by an eastward electric field due to the post sunset F-layer dynamo mechanism. At others hours of the night an eastward electric field can also trigger ionospheric irregularities. As seen from the Doppler data in Fig. 3b, the F-region plumes showed predominantly large upward vertical drifts from 21:50 UT up to 23:10 UT, a downward drift from 23:10 to 23:20 UT and again an upward drift from 23:20 up to 23:40 UT. These fluctuations are coincident with the corresponding strong auroral activity from 20:00 UT up to the midnight period, as can be observed by the AE index. After 23:40 UT, just one bottomside layer remained through midnight (no radar measurements were made after midnight). Note the bottomside layer drifting downward (represented by blue after $\sim 23: 00$ UT in Fig. 3b) and the simultaneous eastward drifts (see the bottom panel). This is also the bottomside behaviour during quiet time conditions.

The zonal drifts of the irregularity structures below $600 \mathrm{~km}$, as seen in Fig. 3c, are predominantly westward during 22:15-22:50 UT and then turned eastward up to the end of the measurements. Such zonal characteristics were also observed by Basu et al. (1996) during the disturbed night (2-3 October 1994), where they found that the irregularity structure below $500 \mathrm{~km}$ moves westward initially and turns to eastward lately. This is the usual zonal velocity characteristic of the bottom-type and bottomside layer under quiet time conditions and this gives an indication that the low altitude ionosphere was not affected by the storm. In contrast to the eastward moving plume during quiet time the plumes observed in our observations during 22:20 to 23:00 UT and from 600 to $800 \mathrm{~km}$ do not show any well-defined eastward motion. On the other hand, it shows one periodic tendency from eastward to westward velocities and could be probably due to the storm. Such periodic zonal velocity characteristics of irregularity structures was also observed by Basu et al. (1996) during storm conditions.

In order to further elucidated the nature and dynamics of the plasma irregularities, Fig. 4 presents the sequence of spectra during 22:00-23:57 UT for the 30-min interval for the 11 April 2001 night. The spectra are plotted every $20-\mathrm{km}$ altitude interval with the lowest altitude as $400 \mathrm{~km}$ at the bottom and the horizontal bars represent the maximum intensity. The spectra above $900 \mathrm{~km}$ at $\mathrm{t}=22: 00 \mathrm{UT}$ in Fig. 4 show an enhanced fluctuation level at all frequencies, as compared to lower altitudes spectra at the same time. The spectra in the intermediate altitudes $(400-1000 \mathrm{~km})$ at 22:30 and 23:00 UT are broad and similar to the earlier observations (Woodman and LaHoz, 1976). They indicate the presence of the fast ascending structures (bubbles). Moreover, the velocities of these structures peak at three different altitudes $(600,800$ and $875 \mathrm{~km}$ ) at $\mathrm{t}=22: 30 \mathrm{UT}$. They indicate the presence of three different bubbles originated from different bottomside structures at different altitudes. It is quite possible that the two top structures were not locally generated and could have drifted over São Luís from other longitudes.
In Fig. 5, the range-time-spectral width is plotted on the same night. The spectral width, as defined by Eq. (21) of Woodman (1985), is obtained by an auto-covariance approach, and is presented in units of $\mathrm{m} / \mathrm{s}$ instead of $\mathrm{Hz}$. In particular, bottom-type and bottomside structures are identified as structures of narrow spectral widths while plume structures are identified as broad spectral width structures. Different bottomside structures at different altitudes are evident from Fig. 5, which were also noted in Fig. 4. It confirms the aforementioned properties of spectra.

\section{Discussion}

In this event, there is evidence that, besides the normal postsunset eastward F-layer dynamo electric field, there was also the prompt penetration of eastward electric fields of magnetospheric origin and westward disturbance dynamo electric fields that lifted the F-layer abnormally during the entire night of 11/12 April, creating conditions for the irregularities to grow and to persist during this night.

The linear growth rate equation in its simplest form, neglecting nighttime E-region conductivity (Ossakow, 1981), is:

$\gamma_{L}^{\prime}=L_{N}^{-1}\left(\frac{E}{B}+\frac{g}{v_{i n}}\right)$,

where $\mathrm{L}_{N}$ is the electron density gradient scale length given by $\mathrm{L}_{N}^{-1}=(1 / \mathrm{N})(\mathrm{dN} / \mathrm{dh}), \mathrm{N}$ is the ambient electron density, $\mathrm{E}$ is the eastward electric field, B is the magnetic flux density, $\mathrm{g}$ is the gravitational acceleration, and $v_{i n}$ is the ion-neutral collision frequency. Hence, the favourable conditions for the instabilities to grow, besides the vertical drift E/B, are a small ion-neutral collision frequency and a steep electron density gradient. From the true height profiles of the two ionograms presented in Fig. 2, it can be inferred that on the storm night, all of the above factors were most favourable. The growth rate $\gamma_{L}^{\prime}$ was calculated using the values of $L_{N}$ derived from true height profiles, and the $v_{\text {in }}$ were obtained from standard atmospheric models. $\gamma_{L}^{\prime}$ was $2.0 \times 10^{-3} \mathrm{~s}^{-1}$ at 22:00 UT (the spread $F$ onset time) on the storm night (11/12 April), which is much larger than its value of $0.3610 \times{ }^{-3} \mathrm{~s}^{-1}$ at $\sim 22: 15 \mathrm{UT}$ on the control night (9/10 April). Similarly, at 07:45 UT, $\gamma_{L}^{\prime}$ was $0.32 \times 10^{-3} \mathrm{~s}^{-1}$ and $-0.4 \times 10^{-3} \mathrm{~s}^{-1}$, respectively, under spread $F$ and non-spread $F$ conditions.

It is pertinent to note that the plumes observed by the radar lasted until about 23:40 UT while the digisonde strong spread $F$ continued up to the post-midnight period and $\mathrm{GHz}$ scintillations showed a secondary peak in the post-midnight period. This suggests that the kilometer to hundreds of meters scale size irregularities responsible for spread $F$ and $\mathrm{GHz}$ scintillations and the 5-m scale size irregularities producing the radar backscatter topside plumes are simultaneously generated, but the small-scale sizes decay faster (Rodrigues et al., 2004). Since there was no radar data in the post-midnight period, it cannot be ascertained if the secondary peak in scintillation is associated with any 


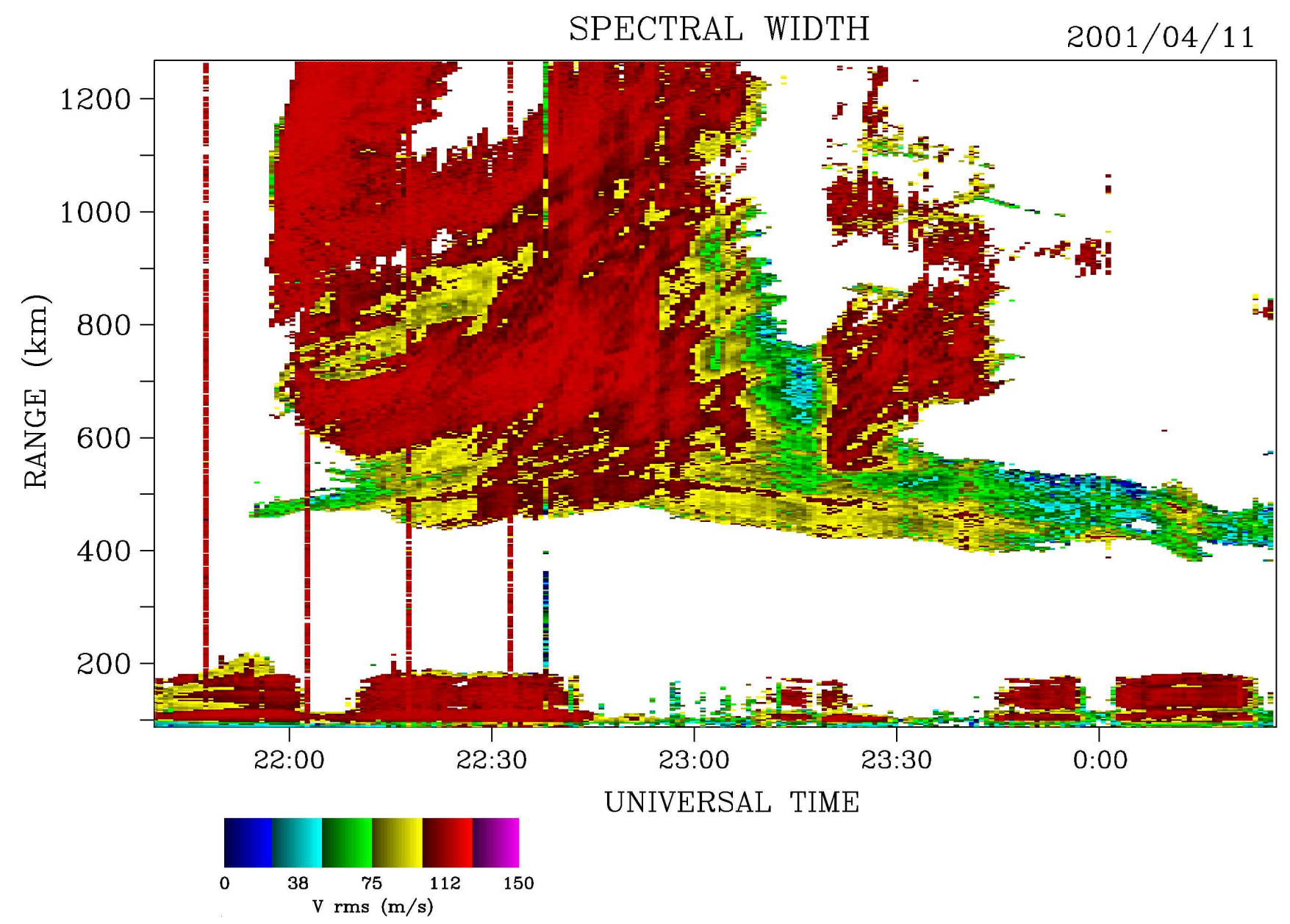

Fig. 5. The Range-Time-Spectral width plot on 11-12 April 2001.

corresponding radar signature. An intriguing question is why the F-layer remained at high altitude all through the storm night. One possibility is that the eastward magnetospheric electric field due to enhanced and decreased magnetospheric convection penetrated directly to low latitudes, and at some time after the SSC, the disturbance dynamo, due to the action of disturbance winds, became effective. Together, these effects might account for this anomalous F-layer behaviour and for triggering the irregularities. The present results (the sustenance of spread and scintillation in the post-idnight period) are in agreement with the frequent occurrence of an eastward disturbance electric field in the 03:00-09:00 UT sector at middle and low latitudes (Fejer et al., 1990; Reddy and Nishida, 1992).

Long-term campaigns involving the São Luís radar are being conducted, and the resulting data, in conjunction with data from GPS receivers, the digisonde, and the magnetometer, will allow us to study in more detail ionospheric irregularities during magnetic storms.

\section{Conclusions}

We have investigated the characteristics of ESF irregularities over the Brazilian equatorial station, São Luís, during the magnetic storm of 11 April 2001 using a variety of techniques. These observations (and also analysing the radar data spectrum) recall that (1) the spread $F$ in the digisonde ionograms was observed at all nights in the period of 9-13 April (Fig. 1 shows data only for the days 10-12 April), but with larger intensity and duration on the storm night 11-12 April, (2) the GPS amplitude scintillations were observed mainly only at the storm night, (3) the radar plumes (topside layers) seen on the storm night reached more than $1200 \mathrm{~km}$ in altitude, its portions located between 600 to $800 \mathrm{~km}$ at 21:50 UT were not preceded by a normal quiet-time bottom-type layer and were drifted from another longitudinal zone, differently from the lower structure that was generated locally and was preceded by the bottom-type layer, (4) the plume from 900 to $1200 \mathrm{~km}$ in the time interval of 21:50 UT to $22: 20 \mathrm{UT}$ is a very turbulent and fast upward structure that probably also drifted over São Luís from the eastern longitude sector since 
this structure is moving westward, (5) the plumes had periodic eastward and westward zonal velocities after 22:20 UT when well-developed quiet-time plumes typically drift eastward, (6) the bottom-type structure below $600 \mathrm{~km}$ height was moving upward and westward and the bottomside structure also below $600 \mathrm{~km}$ height was moving down and eastward, similar to the quiet-time behaviour and gives evidence that they were not affected by this storm, (7) the F-layer remained anomalously high all through the storm night, after its uplifting around 21:00 UT, creating favourable conditions for ionospheric irregularities to grow and persist throughout the night.

The ascent of the F-region during the post-sunset period and its unsual maintenance at anomalous high altitudes throughout the storm night of 11/12 April is interpreted as being due to the combined effects of the prompt penetration magnetospheric electric field and delayed disturbance dynamo electric field to the equatorial ionosphere. The evidence for this is inferred from the VHF radar drift data, high latitude indices, and IMF $B_{z}$ variations. It is found from the height profiles of ionograms that particularly favourable conditions for the R-T instability growth existed on the storm night. On that night, the temporal evolution of the irregularities, as seen by the digisonde, GPS scintillation receivers, and the VHF radar, which are sensitive to different irregularity spatial scales, suggests that all scale sizes (from a few tens of $\mathrm{km}$ to $5 \mathrm{~m}$ in this case) were generated simultaneously and that the smaller scales, seen by the radar, decayed faster than the larger scales observed by the digisonde. However, the GPS amplitude scintillations were observed mainly in the storm night.

The VHF radar RTI (Range Time Intensity) echoes and their power spectra/spectral width for the storm night 11/12 April were used to analyse the nature and dynamics of the plasma irregularities and revealed the coexistence of 3 structures in the altitudinal range of $400-1200 \mathrm{~km}$ around 22:30 UT (see Figs. 4 and 5) and we suggest that one of them was locally generated, presenting the normal bottom-type layer around $500 \mathrm{~km}$, while the other 2 structures that appeared around 22:00 UT in the altitudinal range of 600 to $800 \mathrm{~km}$ drifted from another longitudinal sector. The spectra in Fig. 4, in the altitudinal range of 850 to $1200 \mathrm{~km}$ at 22:00 UT, show an enhanced fluctuation level at all frequencies as compared to lower altitude spectra, and it is drifting upward and westward and probably also drifted over São Luís.

Acknowledgements. The VHF radar at São Luís was established with the financial support from FAPESP under the process 99/00026-0. This work was supported by the NSF grant ATM0080338 to Cornell University. The authors are grateful to B. G. Fejer and M. A. Abdu for the valuable discussions, to A. C. Neto and his team at São Luís for equipments operation and data acquisition. E. R. de Paula is thankful to $\mathrm{CNPq}$ for the partial support under Process 502223/91-0. E. A. Kherani acknowledges the award of the visiting fellowships by CNPq under Process 302122/02-8 and by FAPESP under Process 04/01272-5. K. N. Iyer acknow- ledges the award of the visiting fellowships by CNPq under process $301213 / 00-3$. F. S. Rodrigues is thankful to FAPESP for financial support under Process 00/13325-5.

Topical Editor M. Lester thanks M. Keskinen and another referee for their help in evaluating this paper.

\section{References}

Aarons, J.: The role of the ring current in the generation or inhibition of equatorial F-layer irregularities during magnetic storm, Radio Sci., 26, 1131-1149, 1991.

Abdu, M. A., Sobral, J. H. A., Nelson, O. R., and Batista, I. S.: Solar cycle related range spread- $F$ characteristics over equatorial and low latitude stations in Brazil, J. Atmos. Terr. Phys., 47, 901905, 1985.

Abdu, M. A., Batista, I. S., and Sobral, J. H. A.: Equatorial ionospheric electric fields during magnetospheric disturbances: Local Time/Longitude dependences from recent EITS campaigns. J. Atmos. Terr. Phys., 57, 1065-1094, 1995.

Abdu, M. A., Denardini, C. M., Sobral, J. H. A., Batista, I. S., Muralikrishna, P., and de Paula, E. R.: Equatorial electrojet irregularities investigations using a $50 \mathrm{MHz}$ back-scatter radar and a digisonde at São Luís: some initial results, J. Atmos. Solar-Terr. Phys., 64, 1425-1434, 2002.

Abdu, M. A.: Outstanding problems in the equatorial ionospherethermosphere electrodynamics relevant to spread F, J. Atmos. Solar-Terr. Phys., 63, 869-884, 2001.

Basu, S., Kudeki, E., Basu, Su., Valladares, C. E., Weber, E. J., Zengingonul, H. P., Bhattacharyya, S., Sheehan, R., Meriwether, J. W., Biondi, M. A., Kuenzler, H., and Espinoza, J.: Scintillations, plasma drifts, and neutral winds in the equatorial ionosphere after sunset, J. Geophys. Res., 101, 26 795-26 809, 1996.

Basu, Su., Basu, Sa., Valladares, C. E., Yeh, H.-C., Su, S. -Y., MacKenzie, E., Sultan, P. J., Aarons, J., Rich, F. J., Doherty, P., Groves, K. M., and Bullet, T. W.: Ionospheric effects of major magnetic storms during the international space weather period of September and October 1999: GPS observations, VHF/UHF scintillations, and in situ density structures at middle and equatorial latitudes, J. Geophys. Res., 106, 30 389-30 413, 2001.

Batista, I. S., de Paula, E. R., Abdu, M. A., and Trivedi, N. B.: Ionospheric effects of the 13 March 1989 magnetic storm at low and equatorial latitudes, J. Geophys. Res., 101, 10 887-10892, 1991.

Beach, T. L. and Kintner, P. M.: Simultaneous Global Positioning System observations of equatorial scintillations and total electron content fluctuations, J. Geophys. Res., 104, 22 553-22 565, 1999.

Beach, T. L. and Kintner, P. M.: Development and use of a GPS ionospheric scintillation monitor, IEEE Trans. Geosci. and Rem. Sensing, 39, 918-928, 2001.

Blanc, M. and Richmond, A. D.: The ionospheric disturbance dynamo, J. Geophys. Res., 85, 1669-1686, 1980.

de Paula, E. R. and Hysell, D. L.: The São Luís VHF coherent scatter radar: system description and initial results, Radio Sci., 39, RS1014, doi:10.1029/2003RS002914, 2004.

Fejer, B. G.: Equatorial ionospheric electric fields associated with magnetospheric disturbances, in: Solar wind-magnetosphere coupling, edited by Kamide, Y. and Slavin, J. A., Tokyo: Terra Scientific, 519-545, 1986.

Fejer, B. G., Kelley, M. C., Senior, C., De la Beaujardiere, O., Holt, J. A., Tepley, C. A., Burnside, R., Abdu, M. A., Sobral, J. H. 
A., Woodman, R. F., Kamide, Y., and Lepping, R.: Low- and mid-latitude ionospheric electric fields during the January 1984 GISMOS campaign, J. Geophys. Res., 95, 2367-2377, 1990.

Fejer, B. G.: The electrodynamics of the low-latitude ionosphere: recent results and future challenges, J. Atmos. Terr. Phys., 59, 1465-1482, 1997a.

Fejer, B. G.: Natural ionospheric plasma waves, in: Modern Ionospheric Science, Max-Planck Inst. für Aeron., Lindau, Germany, 216-273, 1997b.

Fejer, B. G. and Scherliess, L.: Time dependent response of equatorial electric fields to magnetospheric disturbances, Geophys. Res. Lett., 22, 851-854, 1995.

Fejer, B. G., Scherliess, L. and de Paula, E. R.: Effects of the vertical plasma drift velocity on the generation and evolution of equatorial spread F, J. Geophys. Res., 104, 19 859-19870, 1999.

Hysell, D. L. and Woodman, R. F.: Imaging coherent backscatter radar observations of topside equatorial spread F, Radio Sci., 32, 2309, 1997.

Hysell, D. L. and Burcham J. D.: Julia radar studies of equatorial spread F, J. Geophys. Res., 103, 29 155-29 167, 1998.

Hysell, D. L. and Burcham, J. D.: Long term studies of equatorial spread $F$ using JULIA radar at Jicamarca, J. Atmos. Solar-Terr. Phys., 64, 1531-1543, 2002.

Kelley, M. C., Hysell, D., and Musman, S.: Simultaneous Global Positioning System and radar observations of equatorial spread $F$ at Kwajalein, J. Geophys. Res., 101, 2333-2342, 1996.

Kikuchi, T. and Araki, T.: Horizontal transmission of the polar electric field to the equator, J. Atmos. Terr. Phys., 41, 927-936, 1979.

Kil, H. and Heelis, R. A.: Global distribution of density irregularities in the equatorial ionosphere, J. Geophys. Res., 103, 407-417, 1998.

Musman, S., Jahn, J.-M., Labelle, J. and Swartz, W. E.: Imaging spread- $F$ structures using GPS observations at Alcântara, Brazil, Geophys. Res. Lett., 24, 1703-1706, 1997.
Ossakow, S. L.: Spread- $F$ theories - A review, J. Atmos.Terr. Phys., 43, 437-452, 1981.

Reddy, C. A. and Nishida, A.: Magnetospheric substorms and night time height changes of the F2-region at middle and low latitudes, J. Geophys. Res., 97, 3039-3061, 1992.

Reinisch, B. W., Bibl, K., Kitrosser, D. F., Sales, G. S., Tang, J. S., Zang, Z.-M., Bullet, T. W. and Ralls, J. A.: The digisonde 256 ionospheric sounder, WITS Handbook, Vol. 2, edited by Liu, C. H., 350, 1989.

Rodrigues, F. S., de Paula, E. R., Iyer, K. N., Kintner, P. M., Abdu, M. A., and Jardim, A. C.: Equatorial spread F irregularity characteristics over São Luís, Brazil, using VHF radar and GPS scintillations techniques, Radio Sci., 39, No 1, RS1S31, doi:10.1029/2002RS002826, 2004.

Scherliess, L. and Fejer, B. G.: Storm time dependence of equatorial disturbance dynamo zonal electric fields, J. Geophys. Res, 102, 24 037-24 046, 1997.

Somayajulu, V. V., Reddy, C. A., and Viswanathan, K. S.: Penetration of magnetospheric electric field to equatorial ionosphere during the sub storm of March 22, 1979, Geophys. Res. Lett., 14, 876-879,1987.

Spiro, R. W., Wolf, R. A. and Fejer, B. G.: Penetration of high latitude electric fields effects to low latitudes during SUNDIAL 1984, Ann. Geophys., 6, 39-50, 1988.

Weber, E. J., Basu, S., Bullet, T. W., Valladares, C., Bishop, G., Groves, K., Kuenzler, H., Ning, P., Sultan, P. J., Sheehan, R. E., and Araya, J.: Equatorial plasma depletion precursor signatures and onset observed at $11^{\circ}$ south of magnetic equator, J. Geophys. Res., 101, 26 829-26 838, 1996.

Woodman, R. F. and La Hoz, C.: Radar observations of F-region equatorial irregularities, J. Geophys. Res., 81, 5447-5466, 1976.

Woodman, R. F. A.: Spectral moment estimation in MST radars, Radi Sci., 6, No 6, 1185-1195, 1985. 